\title{
IMMATERIAL DAMAGE AND SOME TYPES OF ITS COMPENSATION
}

\author{
Asmir Sadiku, PhD. C. 1 \\ 1 South East European University, Faculty of Law, asmirsadiku@gmail.com
}

\section{Article history:}

Accepted 30 March 2020

Available online 31 April 2020

\section{Keywords:}

Damage,

Causing Damage,

Material Damage,

Immaterial Damage,

Compensation of Immaterial

Damage,

Criteria For Compensation

of Immaterial Damage,

Types of Immaterial Damage.

\begin{abstract}
A b s t r a c t
The purpose of any legal system is the regulation and harmonization of actions between people within their respective societies. Now in almost every thesis of this nature you will come across a reference to one of the principles on which the relationship between people should be constructed; the prohibition to cause damage to another, and in case of non-respecting this principle, as it happens in many cases for various reasons, the obligation of indemnity arises, that aims restoring of a situation which was prior to causing of the damage, and the realization of this target is in direct correlation with the nature of the damage caused, and in case of immaterial damage, it is almost unattainable, target, but that does not affect the need to compensate damages of such nature. The issue of immaterial damage compensation is one of the most controversial and current matters in the theory and judicial practice, and this not only because it includes the matters of protecting an individual, his rights to invulnerability as an individual, but even due to the fact that the lack of criteria for the assessment of immaterial damage, influenced to the reference on various criteria, thus creating a change in judicial practice, in regard to the amount of defined compensation for similar cases. This thesis addresses immaterial damage, in regard to its forms of presentation, and then the procedure of immaterial damage compensation and the criteria based on which are assessed; the nature and the extent of the caused damage for the effect of its compensation.
\end{abstract}

\section{Introduction}

Beyond the criteria related to the compensation of immaterial damage, the immaterial damage itself is an institute that is new in itself, and as such we initially find it in French jurisprudence, whereas later, this institute was also developed by German legal theory, thus recognizing a gradual expansion of damage notion, and this development is directly influenced by the concept of personality rights, respectively the rights related to personality such as; rights on liberty, life, name, reputation, etc. All these presents a special category of rights and as such are subject to the protection of private law, except criminal and family law, considering from the constitutional protection which the same enjoy as indivisible, inalienable and invulnerable rights. Considering protection subject, it can be emphasized that differently from material damage, immaterial damage is a generic concept, almost outlined, so difficult to be defined, considering even the terminology used to refer to it, so it has been defined as all damages which are not material in their nature, most commonly noticed as extra-material damage, non-economic damage, moral damage or ideal damage, but there is an growing tendency for it to objectively define the area of lawfully protected immaterial interests. This uncertainty in the terminology of immaterial damage itself, directly influenced on determining the circle of persons to whom this right is addressed, as well as the nature of adequate compensation for the damage suffered, and this uncertainty is caused up to specific situations from judicial practice, making difficulties in proceeding cases of such nature, by providing of merit basis settlement, where the amount of compensation would be satisfactory to the party who suffered the damage, but also to respond to the liability in adequate extent, of the responsible person who caused the damage.

Thus, this thesis will address immaterial damage in the light of these difficulties encountered in judicial practice, by referring relevant cases, combining theoretic and practical aspects, respectively in function of identifying the difficulties of applying 
of current provisions, but even the needs on eventual changes, with a target to a fairer settlement of cases of this nature that have an highlighted sensitivity, considering the nature of vulnerable rights and caused damages, which in many cases are irreversible, and that respectively this makes it necessary to consolidate in the legal context the full concept of "moral damage" and the development of a single system for its calculation.

\section{Meaning of Immaterial Damage}

The Law on Obligational Relationships of Republic of Kosovo, does not provide a detailed definition of immaterial damage, respectively it only refers to the specific types of this damage, whereas the need for its compensation can be derived from general provisions such as the legal provision which highlights that the damage comprises the diminution of property (ordinary damage), prevention of the appreciation of property (lost profits), the infliction of physical or mental distress or fear on another person, and encroachment upon the reputation of a legal person (immaterial damage). Immaterial damage it can also be created separately from material damage, but in most cases it comes along with it, and as a wide and comprehensive category, including within the same "any damage suffered by the infringement of non-property rights and interests which are part of human values, and which are not a subject of direct market economic assessment". The Law on Obligational Relationships of Kosovo, provides some types of immaterial damage which can be compensated, setting as a distinguishing criteria not only the type but also the manner in which it is compensated, so in regard to a type of immaterial damage, such as in the event of a infringement of the right of personality, provides the opportunity of achieving the target even in the absence of compensation, whereas for other types of damage which will be addressed in follow up, monetary compensation is foreseen as the only form of compensation, considering the nature of the damage on which compensation is required.

\section{Indispensable Criteria for Existence of Immaterial Damage}

In any case, either under criteria of proofing of material damage or immaterial damage, it is indispensable the existence of general elements as unlawful action, the damage caused as a result of it, then this action has been committed with guilt and existence of causal link between the action and the damage caused, and that the existence of these criteria which must be fulfilled collectively derives from the legal provision "Any person that inflicts damage on another shall be obliged to reimburse it, unless it is proved that the damage was incurred without the culpability of the former". The damage may be a consequence of acting or omission, but in any case the action is contradiction of interests and rights of the other, protected by legal order or good practice, and respectively affecting of such interests or rights; is the consequence of harmful action or respectively the damage caused to another person, who must prove the causal link between them, as the existence of damage or damage action in itself, does not present grounds for indemnity, as the lack of identification of the action or damage omission, means that the person from whom the compensation will be required is missing, whereas the lack of proof of a respective consequence, makes the claim for damages unfounded. But the lawmaker as a general criteria has foreseen even the existence of the guilt of the causing damage, which may be on purpose and negligence, while from this general criteria has excluded the damage from the objects or dangerous activities, to which are responsible the holder of dangerous object respectively the person dealing with dangerous activity, regardless of the guilt. In this view, it is important to emphasize the fact that from interpretation of this provision it results in the presumption of guilt being therefore taken for granted, and it is the obligation of the person causing the damage to prove that he/she is not guilty, respectively despite that his/her behavior could have been unlawful was found under such circumstances, that it has been impossible for to avoid it.

\section{Types of Immaterial Damage}

\subsection{Compensation of Immaterial Damage Due to Causing of Fear}

Fear is one of the most common forms of immaterial damage, which affects bodily integrity and health damage. The fear presents the subjective element of the injured party, and is a feeling of deep concern, internal psychic experience, unpleasant of the injured party caused by delinquent action of harmful party, in traffic disaster, injuries caused at working place or related to the work. As such, fear can be caused even despite bodily injury and other physical pain. In this way, fear can arise both in the event of an attempted assault but also when the violence is directly caused. The fear can be primary, secondary, direct, indirect, fear of life and fear of healing. To realize the claim for compensation of immaterial damage due to the fear, following criteria must be cumulatively met: a) that the injured subject suffered fear, b) the fear is of high intensity, c) fear has certain duration, fear causes consequences to the injured party, and d) the injured party to file a claim at the competent court for realization of compensation of such damage.

When determining the degree of intensity and duration of fear, the judicial expert must consider the person's age, health status, person's gender, place and time of injury, etc., as the effects are not the same for all. This is stressed, as it is known that in children, women or persons with poorer health status, the fear may be of a higher intensity and of longer duration than in adults, which as such may cause consequences. All these circumstances 
presented in the report of the judicial expert, are considered by the judge in a free assessment, formed on the basis of his/her internal conviction when the judgment is announced.

In judicial practice there are court decisions in which the courts should consider the extent of bodily injury, duration of fear, experienced intensity, adjudicates to the injured party money compensation. So, in a case the Court of Appeals of Kosovo by judgment Ac. no. 2082/2014 dated 18.01.2017, approved the appeal of the respondent, so it amended the judgment of Basic Court in Pristina C.no.2531/2008 dated 06.12.2013, in regard to immaterial damage for sustained psychical pains, thus adjudicated the amount of 2.900 euro, for the suffered fear adjudicated the amount of 2.700 euro, for reducing of life activity adjudicated the amount of 4.600 euro, and on behalf of deformity adjudicated the amount of 2.350 euro.

Compensation of immaterial damage with money due to causing of fear, presents a satisfaction for the injured party, rather than achieving of any lucrative purpose that is not in compliance with the social purpose of this compensation. It should be highlighted that the right on compensation claim of immaterial damage due to the fear is closely related to the personality of the subject who suffered certain fear.

\subsection{Compensation of Immaterial Damage Due to}

\section{Bodily Injury}

This form of immaterial damage compensation is manifested in those cases where the victim sustained extremity fractures, rib fractures, injury of fracture of spinal cord, head fractures or other injuries in the body, so the injured person suffers physical pain and psychics suffering.

In order to obtain the compensation of immaterial damage due to bodily injury, also at this point, cumulatively, following criteria should be met: bodily harm must be caused, bodily harm should cause physical pain or mental suffering, existence of causal link between the bodily injury and caused physical and psychic suffering of the injured party and the existence of responsible subject. Determination for the compensation of this damage is provided by the court, based on the assessment of the judicial expert, as at this point it is very important to ascertain the intensity and duration of the physical pain and mental suffering of the person.

\subsection{Compensation of Immaterial Damage Due to Psychic Suffering}

Psychic suffering presents also one of the forms for the compensation of immaterial damage. Psychic suffering, as a special ground for the compensation of immaterial damage, presents a sense of deep concern; respectively an unpleasant internal experience that occurs under the influence of an external risk, whereby the person suffers emotional and psychic's disorders. This form of compensation of immaterial damage is more difficult to be ascertained, as it depends on the psychic constitution and disposition of the injured party, his mentality and other circumstances.

Law on Obligational Relationship of Kosovo (LOR) Article 183 paragraph 1 and paragraph 2, provides that "Just monetary compensation independent of the reimbursement of material damage shall pertain to the injured party for physical distress suffered, for mental distress suffered owing to a reduction in life activities, disfigurement, the defamation of good name or reputation, the truncation of freedom or a personal right, or the death of a close associate, and for fear, if the circumstances of the case, particularly the level and duration of distress and fear, so justify, even if there was no material damage. Upon the decision on the request for the compensation of immaterial damage, as well as for the amount of the compensation, the court shall evaluate the importance of the violation of goods and the purpose to which this compensation shall serve, also in order not to support the tendencies that are not compatible with the nature and the social purpose thereof".

\subsection{Compensation of Immaterial Damage Due to Deformity}

Deformity as a form of immaterial damage occurs as a result of the infringement of the bodily integrity of the injured subject. Deformity is spoil of the external appearance, of the shape of the human body or any part of it, respectively spoiling of the external appearance of any bodily function. In practice, cases of causing deformity are expressed during injuries caused, during traffic injuries, when using dangerous objects or when dealing with dangerous activities, whereby the injured persons sustains face or head deformations as a result of creating bruises, deformation due to injury or rupture of the hand or foot, or even other parts of the body. After the moment of deformity, loss of the beauty of mentioned person is caused and there is psychic imbalance, a sense of inferiority is created in relation to other members of society, and all of this is reflected in a depressive state, by what often there is a stagnation of the injured person in the profession or in daily life. For the realization of this compensation a deformity should exist, bodily deformation of the injured subject, and deformity to cause spiritual suffering of a certain intensity and duration. The right on compensation for immaterial damage from the deformity is personal and does not pass to the heirs of the injured party. In a real case form Basic Court in Peja - Branch in Klina, by judgment C.no. 418/17 dated 19.12.2018, in regard to the compensation of damage caused by a traffic accident, the 
Court obliged the respondent Insurance Company Scardian, with seat in Pristina, to compensate to the claimant the amount of 4000 euro, on behalf of compensation due to bodily deformity.

\subsection{Compensation of Immaterial Damage Due to Causing Of Death}

Compensation of immaterial damage, due to causing of death, occurs after the death presents a relevant fact to seek the realization of immaterial damage compensation. Most of legislation and judicial practice recognizes this type of immaterial damage.

Law on Obligational Relationsships of Republic of Kosovo (LOR), provides the circle of close family members who are entitled to the compensation of immaterial damage, in case of death or serious disability of the family member. So, Article 184 paragraphs 1 to 4 of LOR provide that "If a person dies the court may award just monetary compensation to his/her immediate family members (spouse, children and parents) for their mental distress. Such compensation may also be awarded to siblings if there was a long-term union for life between them and the deceased or injured party. In the event of a person becoming seriously disabled the court may award his/her spouse, children or parents just monetary compensation for their mental distress. The compensation specified in paragraph 1 and 3 of this article may be awarded by the court to an extra-marital partner if there was a union for life between the partner and the deceased or injured party".

Civil Code of Republic of Albania, Article 643 provided that when e death of a person has been caused, the damage to be compensated is comprised off: "a) living and nutrition expenses for his minor children, consort and parents unable to work who used to be under the responsibility of the dead person, completely or partially, and of the persons who used to live in the dead person's family and who had the right of nutrition by him; b) the necessary expenses of the dead's funeral, according to the personal and family circumstances of the dead person. The person who has caused damage may claim the same protecting means that he would claim to the dead person. The Court taking into consideration all the circumstances of the question might decide the recompense to be given in nature, or in cash, at once or in trances (parts)".

In order to realize the compensation for immaterial damage due to causing of death, the following criteria must be met: the death of a relative is caused, the death causes suffering to his relatives, existence of the causal link between the death caused and the psychic suffering caused, the death to have been caused by unlawful action, and a claim for compensation for immaterial damage must be filed at the court.

\section{Filing of Lawsuit}

In principle, all rights and interests are protected, even the suit for compensation of non-pecuniary damage may also be filed by anyone claiming the cause of such damage, in which claim must specify the damage it claims to have been caused to him/her by the actions of respondent and the amount of compensation required by the same, as a consequence of the damaging action, since the lawmaker has determined monetary compensation as the only form of compensation, excluding of case of the infringement of a personal right the court may order the publication of the judgment or a correction at the injurer's expense or order that the injurer must retract the statement by which the infringement was committed or do anything else through which it is possible to achieve the purpose achieved via compensation.

Considering even the nature of such cases, the lawmaker has provided that in addition to the general territorial jurisdiction, the lawsuit may also be filed in the court in whose territory the damaging action has been committed or the court in whose territory the consequence of the damage arose, whereas in cases of death or serious bodily injury, the lawsuit may also be filed with the court in the territory of which the claimant has his/her residence, respectively the emplacement. From the reading of the legal provisions, it results that in cases where the injured party accepts the compensation offered by the insurance associations or special compensation funds, the same is not entitled to claim through the lawsuit additional compensation for the damage caused, but there are exemption situations related to the unawareness of parties on the consequences of accepting such amounts of compensation, and in this respect the European Court of Human Rights has in some cases found that the parties' disability that through legal remedies in this case a lawsuit, to seek additional compensation, constituted a violation of Article 6 (1) of the European Convention (the right to a fair trial), arguing that the circumstances under which the victims acted, was reasonable to believe that they had the right to start or continue using legal remedies even after the acceptance of the compensation offer, whereas were not sufficiently clarified on consequences caused by accepting of available funds.

\subsection{Lawsuit Statutory Limitation on Damage Compensation}

The institute of statutory limitations is an important civil law institute, through which legal deadlines have been settled within which judicial protection might be seek for an alleged right. In this regard, lawmaker has foreseen that compensation claims for damage inflicted shall become statute-barred three (3) years after 
the injured party learnt of the damage and of the person that inflicted it, known even as subjective deadline, as it is related to injured party knowledge and its causing party, whereas in each case the claim shall become statute-barred five (5) years after the damage occurred, which is objective deadline, as it is related to the event as objective circumstance, from where the deadline begins. However, there are two exceptional cases of these preclusion deadlines, initially considering a totally specific circumstance related to the juvenile age in the case of created damage by the act of sexual abuse, it is provided that statutory limitation of the claim in this case is fifteen (15) years after the juvenile has reached the age of maturity and secondly, it is related to claims for compensation of damage caused by criminal offences, where the statutory limitation deadline is conditioned by the time set for statutory limitation of criminal prosecution, always if a for a criminal prosecution a longer deadline of statutory limitation is provided.

\subsection{Burden of Proof}

In court proceeding, the court should require the parties to present evidence of any facts on which the conduct of the proceeding depends or any decision making during this process and in the case of filing a lawsuit, the plaintiff must attach all evidence to the lawsuit, through which he/she claims to prove his/her allegations, respectively in the present case, the damages caused by the respondent, either in their nature and also at the height of the intensity they do have. In this regard, the plaintiff must, through the evidence presented or those proposed to be administered, prove that the damage actually occurred as a result of the respondent's adverse action, but does not mean that the consequence of the damage, respectively the effects have been fully manifested, but as such must be manifested, that is, projectable in a reasonable future, then the damage must be specified, so as to be related to the plaintiff specifically and individually, and the damage must also be "quantifiable", indeed the exact monetary value of the alleged damage must be stated, even tough the Court is not bound by the parties' allegations, but has freedom of action to assess the amount of the damage itself, which is almost in all cases it does so by engaging of an independent expert. But, considering the subjective nature of this damage and particularly its character-appearance, whether in the form of personality infringement, pain or spiritual suffering, it must be assessed as proven by the plaintiff's own proving of the unlawful fact of the third and the link of this fact with the moral infringement suffered, according to the principle of causal regularity, although even the lawmaker itself has related to specific reports and circumstances, the amount of compensation, which is certainly due to the nature and intensity of the pain since the mere presumption that the closer the family or coexistence of sex is, the more severe the emotional distress and pain of the relative of the injured party or victim, thus, the higher the amount of moral compensation to be imposed by the court is. In this regard, it is important to mention the fact that in cases of damage caused by a criminal offense, and where there is a meritorious decision in the criminal proceedings in respect of that event, and the compensation of damage is required in civil proceedings, then the existence of the damage and causing of it, it is taken as proven and that in civil proceedings, only the amount of damage should be set, and in this case, the plaintiff, when filing of the claim, also attaches the final decision of the relevant court issued in criminal proceedings. However, in addition, the plaintiff bears the burden of contention (onus contestatio), which means that the plaintiff must declare about the allegations of the opposing party, as in another situation, these facts can be considered uncontested by the court.

\section{Expert Engagement}

Almost in all European systems, medical reports serves as ground for the assessment of the damage caused. The Law on Contested Procedure provides that "whenever for proving or clarification of facts or certain circumstances, there is a need for professional knowledge that case Judge does not have", an expert of certain activity should be appointed, and this should be done as result of proposal of parties in proceeding, which are interested of obtaining of evidence through expertise. The role of the expert in court proceeding of this nature, respectively in cases when the civil proceedings takes place for lawsuits on damage compensation, it is very important, since there are respectively experts those who determines the nature and extent of the damage. Some of the most common types of expert witnesses on personal injuries includes the Accident Reconstruction Experts, who uses engineering principles to describe how the accident happened and to determine the most likely cause of the accident, medical experts who concludes the cause and extent of injuries, the most likely cause of pain and current condition, and the need for future medical care, financial experts concludes financial losses by qualifying such items as loss of earning capacity, future medical expenses and permanent injuries, mental health experts, who concludes emotional-psychological or psychological damage due to the damage caused, the manner how this will affect your life. The opinion of the expert or experts is assessed by the court as any other evidence, when it does not convince their opinion it must justify the refusal in the final decision, but may also engage another expert.

\section{Criteria for Imposing of Damage}

As much as it is clear that no price can compensate a pain, that no amount of money can restore lost function, just as the existence of consistent theoretical criteria or principles in assessing damages of this nature is unclear, apart that compensation should 
be aimed at achieving a dual purpose, in one hand the victim's satisfaction and on the other the punishment for causing of damage. The lawmaker in Kosovo was satisfied by conditioning the settlement of compensation based on case circumstances, in particular their intensity and duration of the caused pain, declaring that the court must take care of the importance of infringing the good and the purpose whom this compensation serves, that the same should be in compliance with its nature and social purpose. In this regard, it is important to refer to the regulation on the criteria for the assessment of immaterial damage from auto-liability, drafted by the Central Bank of the Republic of Kosovo, as a good majority of cases are due to accidents of this nature and this regulation presents some criteria on the basis of which certain amounts of compensation have been imposed, such that in the case of spiritual pain due to a decrease in overall life activity, as criteria was considered the type of injury, the part of the body exposed to the injuries, the age of the injured person and the percentage of overall activity decrease, at compensation for bodily pain the nature of consequences is taken into account, whether permanent or temporary, in the case when are permanent, if the reduction in life activity is below $30 \%$ or above $30 \%$, whereas the amounts within these percentages are imposed based on pain intensity, especially severe intensity, with severe intensity, medium intensity, in case of fear the intensity and duration of the fear related to spiritual pain due to deformity has been considered, as criteria was considered the high degree of deformity, low medium, gender and age of the injured person, whereas in the case of compensation for spiritual pain due to the death or high serious invalidity of a close relative, as assessment criteria for the compensation values was considered the proximity to deceased person or to whom was caused high serious invalidity. Although initially it seems that within these criteria a fair assessment of the damage caused can be summarized, in a more concrete review, it is evident that these criteria as such, are superficial and do not reflect fairly whole consequence of the adverse action, although such a regulation with tracking tables does not oblige the court when deciding in context of this nature, judicial practice investigates a corresponding in imposing of amounts that are relatively equivalent to those offered by insurance companies. Beyond the intensity and duration, that are objectively approximately quantifiable, taking into account the nature of the injury it can determine even its duration and intensity, there are specific circumstances, that for the authors of this thesis must acquire a substantial weight in determining of the compensation, highlighting the fact that even under the conditions of the existence of infringement of personality rights at a low intensity or short duration, the injured party is entitled to a fair money compensation, since the recognition of such damage, is a satisfaction on itself, beyond the specific amounts that may be set in relation to the damage caused. The assessment of the respective circumstances of the case, such as the subjective conditions of the injured person; age and individual degree of sensitivity to the infringement suffered, his commitment to the moment of infringement, but also the conduct of the causing damage in relation to the event and infringed persons, gives a special dimension to each case, as in all cases the events are experienced in various manners, which are respectively above-mentioned circumstances, that are crucial in this respect, considering that individual characteristics of the victim may increase or reduce the depth (degree) of suffering. If we do refer to aesthetic damage, it is not sufficient only the degree of deformity caused, but also the respective consequences on the life of the injured person, which depends on age, occupation, his engagement, family status, and other elements which determines specific weight of the damage caused, as for a person engaged in the field of modeling even a minimal damage, would be essential as it would deprive him/her of his primary and possibly only engagement in relation to another person, and considering his occupation and his engagement, such injury of that nature and to that degree would be quite insignificant, then, being young and furthermore unmarried, or engaged in any sport, where the appearance has its own significance, suffering of any deformity even at the lowest rate, results with very high consequence.

Thus, compensation should not be related to the degree of deformity, but its result, respectively the relative consequences that such an event has caused on the life of the person who suffered it. The lawmaker did not specified as a special circumstance the financial situation or economic opportunity of causing of damage to be considered, but such circumstance may be derived considering highlighting of the fact that compensation should not be in contradiction to the social purpose in whose function has been foreseen and in this respect, the economic opportunities of the person causing the damage must be a circumstance which should be considered, because if full compensation would be an oppressive burden on the defendant, the same should be reduced.

\section{Conclusions}

It is evident that the amount of compensation should be defined considering that in one hand, the amount of compensation should not distort the efficiency and cost-effectiveness of insurance systems or welfare, and in the other hand aiming the full compensation of the damage caused. Surely that agreeing of these two principles, on which this entire process must be structured, due to its subjective and internal nature, can not be calculated on tables and schemes estimated only for this purpose, or criteria which refer under abstract conditions, such as intensity or duration, but that the court, relying on the principle of rendering justice according to its internal conviction, established by 
considering all the circumstances of the case in their entirety, relying even on eventual normative criteria applicable to the nature of the infringed right or, in their absence, criteria and assessment elements consolidated by judicial practice in solving analogous cases or relevant extrajudicial experience, to define the extent and nature of the compensation in compatibility with the damage caused.

\section{References}

1. Law on Obligation Relations of the Republic of Kosovo, Law no. 04/L-077, dated 10.05.2012, article: 136,137, 155, 182, 183, 184, 357

2. Lubisha Milloshevic, Law on Obligation, Pristina, p., 150

3. Decision no.12, dated 14.09.2007 of the Civil College of High Court Republic of Albania

4. Nergjivane Dauti, Law on Obligation, Pristina, 2004, p., 197-200

5. Afet Mamuti, Civil Liability for Damage Compensation in Macedonia (Doctoral Dissertation), Tirana, 2013, p., 165-168

6. Judgment, C.no. 418/17, dated 19.12.2018, issued by the Basic Court in Peja - Branch in Klina

7. Judgment, Ac.no.2082/2014, dated 18.01.2017, issued by the Court of Appeal of Kosovo in Pristina

8. Civil Code of the Republic of Albania, Law no.7850, dated 29.7.1994, article 643

9. Alajdin Alishani, Law on Obligation, Pristina, 2002, p., 560

10. Law on Contested Claim of the Republic of Kosovo, Law no.03/L-006, dated 30.06.2008, article 47, 356

11. Michel Cannarsa, Compensation for Personal Injury in France,p., 11-12

12. Altin Shegani, Ylli Pjetërnikaj, Valbona Nano, E drejta - Law, no.1-4/2016, p., 41

13. Ina Hoxhaj, Assertion and silence as a means of proof in civil trial, "Lawyer", no.26, 2018

14. W.V.Harton Rogers, Comparative Report in Damages for Non-Pecuniary Loss in a Comperative Perspective 246 (W.V. Harton Rogers ed.,2001) at 268-75, in G.Comande, Doing Away with Inequality in Loss of Enjoyment of Life, op.J.,Vol.1/2009, paper n.2 pp.1-18, p., 5

15. Regulation on Criteria for the Evaluation of NonMaterial Damage from Liability, approved by the Central Bank of the Republic of Kosovo, dated 15.09.2016, article 31-34
16. Erdelevsky, A.M. (2004). Moral damage: analysis and commentary of legislation and judicial practice. 3-rd ed. Wolters Kluwer, p., 103

17. Lars Noah, Comfortably Numb: Medicalizing (and Mitigating) Pain-and-Suffering Damages, 42 U. Mich. J. L. Reform 431 (2009). Available at: https://repository.law.umich.edu/mjlr/vol42/iss2/5, -p.,452460 